\title{
JÜRGEN HABERMAS. UNA BIOGRAFÍA
}

\author{
JÜRGEN HABERMAS. EINE BIOGRAPHIE
}

\author{
Iliana Melero Monagas \\ DOI: 10.26754/ojs_arif/arif.202024865
}

Müller-Doohm, S., (2020), Jürgen Habermas. Una biografía, Madrid: Taurus.

Si caminásemos hoy por alguna ciudad alemana, y no anduviésemos demasiado atentos, es posible que llegáramos a tropezar en la acera con un Stolperstein. La traducción de esta palabra al castellano es precisamente 'piedra del tropiezo'. Obra de Gunter Demnig, su intención: romper el ensimismamiento de nuestra cotidianidad, y traer al presente la memoria de las víctimas del Holocausto.

Podemos considerar a la inabarcable obra de Habermas también como un Stolperstein. Esta Stolperstein filosófica trata de romper nuestros automatismos perceptivos, y traer al presente la necesidad de reflexionar en un modelo de sociedad que no recaiga en mentalidades fascistas (Müller-Doohm 2020: 44). Jürgen Habermas, que ha llegado a consagrarse como uno de los filósofos alemanes más importantes después de Marx, vivió en primera persona el horror de la Segunda Guerra Mundial. Habiendo nacido en Düsseldorf en 1929, por su edad y una serie de casualidades, se libró de tener que luchar en el frente de una guerra ya perdida. Lo que Günter Gaus o Helmut Kohl — no hay seguridad de la autoríadenominaron la generación de 'la gracia del nacimiento tardío'. Esa generación adquirió una conciencia distinta a la de sus padres. "Hemos sobrevivido, y ahora tenemos que comprometernos" (Müller-Doohm 2020: 44), afirmó Habermas en el curso de una entrevista. Frente al silencio abochornado de sus padres, que legitimaba los crímenes fascistas, los coetáneos de Habermas se comprometieron con la idea norteamericana de democracia a través de la reeducación. Solo se podía vislumbrar ese camino en una Alemania reducida a ruinas, fruto de ideales decimonónicos nacionalistas, también ya quebrados. Si la democracia era la promesa de no volver a incurrir en el horror totalitario, era porque garantizaba el respeto a valores universalistas. A la defensa esperanzada en estos valores consagró Habermas su obra, y también su vida. 
El núcleo de la obra habermasiana es el intento de "aclarar las condiciones bajo las cuales los propios implicados pueden responder racionalmente tanto preguntas morales como preguntas éticas" (Müller-Doohm 2020: 20). Frente a alguna forma de totalitarismo o sistema hobbesiano disfrazado de capitalismo salvaje, Habermas afirma: veritas non auctoritas facit legem. Es la verdad, y no la autoridad, la que determina la ley (o al menos, la ley legítima). De esta máxima se deriva que quien no reconozca una esfera de normatividad, no podrá criticar los sistemas autoritarios. Fascistas o capitalistas, pues, como dijo Horkheimer, "quien no esté dispuesto a hablar de capitalismo, debería guardar silencio también sobre el fascismo" (Horkheimer 1988/1939: 308).

La biografía que ha compuesto el sociólogo Stefan Müller-Doohm nos brinda la oportunidad de conocer la progresiva constitución de las ideas del filósofo de Düsseldorf en su contexto de aparición. No se queda en la mera anécdota, ni en una pieza de periodismo amarillista, sino que proporciona la perspectiva de la microhistoria a través de la cual se nos permite comprender los principales hitos de la historia alemana - y a través de ella, europea - del siglo XX. Müller-Doohm propone una metodología guiada por la dialéctica individuo-sociedad, a través de la cual podemos evitar la mirada aplanadora de los grandes relatos, así como evitar que los mitos en los que devino la Ilustración fallida nos impidan ver lo concreto: lo que aconteció. Y a la vez, a través de un movimiento de autorreflexión desde la piel de nuestro protagonista, podemos captar diacrónicamente la génesis de sus conceptos y teorías en el curso del diálogo vivo entre intelectuales contemporáneos que han acabado conformando no sólo la opinión pública de su momento histórico, sino formando parte del canon filosófico occidental. Es de hecho emocionante seguir el curso de la vida del filósofo biografiado, y descubrir cómo fue conociendo a las grandes personalidades del siglo. Tuvo ocasión de conocer a otros filósofos como los miembros de la Escuela de Fráncfort, Hans-Georg Gadamer, Hannah Arendt, Karl Popper, Richard Rorty, John Rawls, Charles Taylor, Judith Butler, Jacques Derrida, Michel Foucault, entre otros. Pero además fue invitado para hablar con Willy Brandt — que fue canciller socialdemócrata en Alemania Occidental—, así como a impartir una conferencia en la Academia Católica en Múnich frente a Joseph Ratzinger — antes de ser Benedicto XVI—. También pudo debatir con Tariq Ramadan — reputado defensor de los derechos de los musulmanes en Europa- Cabría añadir una larga lista de encuentros con personalidades influyentes o culturas diversas, porque Habermas ha realizado una inmensa cantidad de viajes. Los más inesperados de todos, pueden ser sus destinos en China o Japón, donde él mismo se sorprendió de encontrar un público tan lector de sus obras. 
Para exponernos esta valiosa información, Müller-Doohm se basa en intervenciones de Habermas en la prensa, la obra filosófica habermasiana, e incluso en cartas que no llegaron nunca a enviarse. No pretende Müller-Doohm representar cada hecho de la vida de Habermas - algo que solo puede ocurrir en un cuento de Jorge Luis Borges - sino señalar eventos relevantes desde los cuales permitirnos pensar el presente desde Habermas, de quien dijera en 2012 Ronald Dworkin que "no es solo el filósofo vivo más famoso del mundo, sino que su propia fama es famosa" (Müller-Doohm 2020: 446). Tampoco es la pretensión de esta reseña resumir todo lo que nos cabe encontrar en la obra de Müller-Doohm. Sin embargo podemos anticipar algunas líneas maestras para asomarnos por la trayectoria de nuestro filósofo.

Nacido con una fisura palatina que le perjudica la calidad del habla, Jürgen Habermas nunca se ha identificado con la ideología glorificante de la patria. Más bien lo ha hecho con la mirada del excluido, a la que más tarde, en 1977 durante una visita a Gershom Scholem en Israel se referirá como la mirada de los exiliados. Esa mirada que hemos de dirigir "hacia nosotros mismos, para identificar como amputaciones de la vida las partes enajenadas, reprimidas y anquilosadas" (MüllerDoohm 2020: 220).

Tras su experiencia bélica el joven Habermas se sintió inclinado por estudiar medicina, posteriormente se inclinó hacia una formación humanística, por influjo de su tío Peter Wingender, que le animó a leer, entre otros libros, los Prolegómenos de Kant. Como estudiante preuniversitario en Gummersbach destacó por sus capacidades intelectuales. Llegó a presentarle a uno de sus profesores de bachillerato una refutación del marxismo. Jürgen, como todos sabemos, acabaría dedicándose a la Filosofía.

En su tesis de habilitación, El cambio de la estructura de la esfera pública - traducida al castellano como Historia y crítica de la opinión pública-, obra clave de su pensamiento, analiza la conformación del espacio de intercambio recíproco de razones fundadas. Espacio en el que se desenvolverá el propio Habermas con sus idas y venidas como intelectual crítico de la sociedad. Muchas veces galardonado, otras repudiado, tantas malinterpretado. Ello no fue óbice para participar en la crítica de problemas sociopolíticos de su presente. Ante los problemas cabe el miedo y el silencio, o la valentía de quien toma la palabra. Habermas encarna el riesgo de la crítica. No querría él ser encumbrado como una especie de héroe de la mitología que cabe trazar en la historiografía del siglo XX, pues, en palabras de Joseph Roth, después de la Primera Guerra Mundial "el gran drama se quedó sin héroes" (Roth: 2020/1926: 126). Habermas declara no necesitar ya más alabanzas, pero 
bien merece su valentía por no guardar silencio o no dejarse amedrentar, todavía hoy, una laudatio. Porque como hemos dicho, el silencio es legitimador de la violencia. Es menester defenderle de la impostura de ciertas etiquetas mal atribuidas o caricaturas teóricas reduccionistas. En una entrevista realizada en 1993 por Wolfram Schütte y Thomas Assheuer, ante la pregunta de si debemos asociarle a la "Escuela de Fráncfort", responde: "Las etiquetas que les cuelgan a las teorías más bien dicen algo acerca de la historia de la repercusión de los malentendidos que acerca de la teoría misma. Esto mismo se puede decir también de ciertas palabras sintomáticas como 'discurso' o ‘comunicación sin dominación'. Ya puestos a comprender los resultados de una teoría para ponerlos de relieve, al menos hay que referirlos a los problemas de los que tal teoría procede". (Müller-Doohm 2020: 20)

¿Es pues Habermas continuador de la tradición de la Escuela de Fráncfort? Para responder a esta cuestión, podemos preguntarnos antes, ¿qué es la Escuela de Fráncfort? (1) Un proyecto que no fue: la dialéctica de Horkheimer que quedó en fragmentos y aforismos. La fue abandonando progresivamente por encontrarse paradójicamente absorto en sus labores de burócrata como director del Instituto de Investigación Social. (2) Una teoría crítica sin coherencia, como apuntó Habermas en los 60 (Müller-Doohm 2020: 19). (3) Unos fundamentos teóricos - marxismo ortodoxo, residuo metafísico no naturalista- de los que cada vez Habermas se alejará más.

Y sin embargo, Habermas, que fue ayudante de Theodor Adorno, le defendió en 1963 contra Karl Popper en la que posteriormente sería llamada la "disputa con el positivismo". Esta polémica se dirigía a través de Popper contra todo cientificismo. Con su característico fervor por el debate, Habermas contribuyó a enardecer dicha disputa.

$\mathrm{Y}$, sin embargo, decimos, en su estancia en Starnberg en el Instituto Max Planck trató de retomar el proyecto embrionario de la así llamada Escuela de Fráncfort, bajo la pregunta de: “¿Cómo se puede recuperar el dominio de la disposición técnica para el consenso de ciudadanos que actúan y negocian?” (Müller-Doohm 2020: 199)

Pero pese a estas defensas y acercamientos, hubo también retrocesos: abandonó Habermas en 1959 su puesto en el Instituto de Investigación Social, para terminar su tesis de habilitación gracias a una beca que recibe con la ayuda de Gadamer. Sustituyó en 1964 a Horkheimer en su cátedra de Sociología y Filosofía en la Universidad de Fráncfort, pero no quiso sustituirle en 1970 como director del Instituto (Müller-Doohm 2020: 187), a pesar de ser ya reconocido como uno de los grandes intelectuales de Alemania en esa fecha. Tras la muerte de Adorno 
en 1969 queda un hueco en la Universidad de Fráncfort y en la cultura de la ciudad homónima. A pesar de ser Adorno insustituible, Habermas "es consciente de las expectativas que ahora hay puestas en él, sobre todo con vistas a la prosecución de la teoría crítica" (Müller-Doohm 2020: 182), y sin embargo "proseguir con lo mismo" sin más, no va con él. Afirma que "solo permanecen vivas aquellas tradiciones que en circunstancias modificadas se modifican a sí mismas".

No quiso Habermas heredar un nombre o una posición de prestigio asociado a una teoría elevada a dogma, sino que más bien conquistó él dicha posición como intelectual reconocido a base de una obra inabarcable, y una presencia como hemos dicho muy activa en la esfera pública. Como dice Wiggershaus (Wiggershaus 2009: 815), quizás podamos asociar a la categoría 'Escuela de Fráncfort' con más rigor únicamente los nombres de Adorno y Horkheimer, y en torno a ellos otros autores coetáneos; reservando la categoría 'teoría crítica' para la propuesta filosófica de esta primera generación que después Habermas continuó.

Así, la tradición se modificó a sí misma de la mano de Habermas, asumiendo un cambio de paradigma en la fundamentación de la teoría. Por la influencia del pragmatismo americano Habermas se sitúa entre los teóricos del llamado giro lingüístico, y cada vez más irá integrando la teoría de la evolución en un naturalismo débil en el que debe de haber siempre espacio para pensar la voluntad como principio de la acción de los individuos responsables. Al pesimismo optimista de Benjamin, o la desesperanza esperanzada de Adorno basada en su concepto negativo de racionalidad dominadora, Habermas contrapondrá una razón positiva, constitutiva de nuestros procesos de entendimiento y socialización, y posibilitadora por tanto de una Ilustración que se domine a sí misma.

Desde el punto de vista de Habermas, la forma mediante la cual las democracias de los Estados Nación pueden, desde 1989, evitar que desarrollen tendencias dominadoras o neofascistas, es romper la fundamentación de la categoría ciudadanos en la idea de etnia o nación, y centrarse en un territorio que mira más allá de sus fronteras a una unión cosmopolita. Concretamente Habermas ha argumentado con vehemencia durante muchos años sobre la importancia de una unión política europea, garantizada sobre el vínculo de una Constitución. Ese reto todavía está por ser asumido, sirva esta Stolperstein discursiva para recordar su ferviente necesidad.

Iliana Melero Monagas

Universidad de Zaragoza ili.melero@gmail.com 


\section{BIBLIOGRAFÍA}

Adorno, T. W. (1987): Minima Moralia, Madrid: Taurus.

Adorno, T. W. (2007): Dialéctica de la Ilustración, Madrid: Akal.

Horkheimer, M. (1988): Die Juden und Europa. In: Gesammelte Werke. Band 4, Frankfurt am

Main: Zeitschrift für Sozialforschung.

MülLer-Doohm, S. (2020): Jürgen Habermas. Una biografia, Madrid: Taurus.

Rотн, J. (2020): Años de hotel: postales de la Europa de entreguerras, Barcelona: Acantilado.

Wiggershaus, R. (2009): La Escuela de Fráncfort, México: Fondo de Cultura Económica. 